УДК 808.1

ББК 81.2-5

DOI: https://doi.org/10.17308/lic.2021.2/3410

\title{
РАЗВИТИЕ ЛИНГВИСТИЧЕСКОЙ КРЕАТИВНОСТИ: ТЕХНИКИ ФОРМИРОВАНИЯ ИДЕЙ
}

\author{
Е. М. Александрова \\ Российская академия народного хозяйства и государственной службы \\ при Президенте Российской Федерации
}

\section{DEVELOPING LINGUISTIC CREATIVITY: IDEATION TECHNIQUES}

\author{
E. M. Aleksandrova \\ Russian Presidential Academy of National Economy and Public Administration
}

\begin{abstract}
Аннотация: статья посвящена проблеме развития лингвистической креативности. Одной из наиболее сложных задач, требующих творческого подхода, является создание креативных текстов, в том числе нейминг (naming), связанный с созданием уникального названия или заголовка, основанного на языковой игре. Решению подобных творческих задач способствует умение применять техники формирования идей (Ideation techniques). Было рассмотрено более ста вариантов существующих техник, отобранных методом сплошной выборки, имеющих разное предназначение и степень сложности. Определен и описан набор из восьми техник, которые могут быть использованы в индивидуальной работе, адаптированы и применены к решению задач, связанных с созданием креативного текста. Выявленные техники апробированы при решении нейминг-задачи, связанной с созданием названия на русском и английском языках, содержащегг языковую игру, для книги, посвященной исследованию языковой игры как лингвистического феномена и проблем ее перевода. Было выявлено, что комплексное использование техник способствует улучшению количества и качества вариантов решения задачи, помогает избежать тупиковых ситуаций и, таким образом, сэкономить время. Было сформировано 35 вариантов названий (18 русских, 15 английских, а также 2 названия, сочетающих в себе языковые единицы двух языков). Наиболее продуктивными оказались техники, имеющие более высокий уровень структурной сложности, требуюшие бо́льших ресурсов и времени (Морфологическая матрица, SCAMPER и Метафоры). Исследование показало, что комплексное использование техник способствует значительному повышению лингвистической креативности. Материаль статьи имеют практическую иенность как для преподавателей филологических дисиилин для развития лингвистической креативности у студентов, так и для практикующих писателей, журналистов, копирайтеров и переводчиков для решения профессиональных задач.
\end{abstract}

Ключевые слова: креативность, филология, языковая игра, техники формирования идей, копирайтинг, нейминг.

Abstract: the article is devoted to the problem of linguistic creativity development. One of the most difficult tasks that require a creative approach is the formation of creative texts, including naming, which involves the creation of a unique title, or heading based on the use of wordplay. The ability to apply Ideation techniques can contribute to the solution of creative tasks. We considered over one hundred existing techniques selected by using the continuous sampling method, with different purposes and degrees of complexity. We identified and described the set of eight techniques appropriate for individual usage, that can be adapted and applied for the problems of composing a creative text. The identified techniques were tested on the naming-task aimed at the creation of a title in Russian and English containing a wordplay for a book devoted to the study of the wordplay as a linguistic phenomenon and the problems of its translation. It was revealed that the complex use of techniques helps to improve

(C) Александрова Е. М., 2021

Контент доступен под лицензией Creative Commons Attribution 4.0 License.

The content is available under Creative Commons Attribution 4.0 License. 
the quantity and quality of ideas, helps to avoid impasses and save time. 35 variants of names were formed (18 Russian, 15 English, as well as 2 names combining the language units of two languages). The most productive techniques were Morphological Matrix, SCAMPER, and Metaphors which have a higher level of structural complexity and require more resources and time to apply. It was revealed that the use of techniques contributes to a significant increase in linguistic creativity. The materials of the article are of practical value both for teachers of philological subjects to develop linguistic creativity among students at the stage of higher education, as well as for practicing writers, journalists, copywriters, and translators to solve the professional problems.

Key words: creativity, philology, wordplay, ideation techniques, copywriting, naming.

\section{Введение}

Исследование креативности с разных точек зрения и на разном материале в наши дни получает все большее распространение. Актуальность данной работы, посвященной проблемам развития креативности, обусловлена как недостаточной изученностью данного феномена, так и тем, что именно креативность становится неотъемлемым условием востребованности специалиста в эпоху искусственного интеллекта, когда большинство рабочих процессов, не связанных с использованием творческого подхода, рано или поздно может быть автоматизировано.

Проблема развития креативности формирует такие направления исследований, как «признание на уровне государства проблемы развития креативности в качестве важного условия развития современного общества; понимание культурной и социальной обусловленности проблемы развития креативности; разработка современных методов и форм, позволяющих осуществлять работу по развитию креативного потенциала личности и внедрять их в учебный процесс; формирование грамотной профессиональной позиции педагога как полноценного участника креативного процесса» [1, с. 123]. Таким образом, развитие креативности на каждом этапе получения образования становится важным фактором формирования необходимых компетенций специалиста будущего.

Креативность становится объектом исследований представителей различных направлений науки и искусства, при этом большая часть работ характеризуется междисциплинарной направленностью. Значительное внимание изучению различных аспектов креативности уделяется в работах педагогов (см., например, [2-4] и др.), филологов, а также представителей других профессий, чья работа связана с созданием текстов, писателей, журналистов, копирайтеров и т. д. (см., например, [5-7] и др.). Изучая феномен креативности, ученые дают ему определения в соответствии с целями и направлениями своих исследований.

Понятие креативности. В большинстве случаев креативность определяется либо как умение творчески подходить к решению проблем (см., например, [8, p. 22; 9, с. 98]), либо как способность создать новый продукт, который будет инновационным и востребованным (см., например, [10, p. 97; 11, с. 5]). В рамках данной работы под креативностью понимается способность индивида находить нестандартные способы решения проблемы и создавать инновационный продукт, который будет востребован в определенном контексте.

Лингвистическая креативность и ее типь. Умение творчески подходить к решению задачи и созданию нового продукта является неотъемлемой характеристикой лингвистической креативности. Существует множество подходов к определению лингвистической креативности. Лингвистическая креативность определяется как способность использовать оригинальные, нестандартные стилистические приемы и средства выражения мысли [12, с. $163 ; 13$, c. 20]; как умение работать со словом [14, с. 311]; как способность личности «к извлечению, накоплению и использованию новых знаний по иностранному языку, способствующих ее самореализации, самосозиданию» $[15$, с. 39]; как «комплекс способностей к созданию новых идеальных продуктов с помощью средств родного и/или иностранного языка, продуцированию устных и письменных высказываний на основе дивергентного мышления, сопряженный со стремлением к творческой деятельности» [16, с. 11] и т. д. В ряде случаев учеными используется термин «вербальная креативность», которая связана с механизмами лингвокреативного мышления, в основе которого лежит «способность говорящих к ломке и переключению ассоциативных стереотипов, созданию нового речевого продукта на базе переработки уже существующего языкового материала» $[17$, с. 68 ; 18$, c. 30$]$.

При объединении существующих подходов в рамках данной работы под лингвистической креативностью понимается способность индивида распознавать, передавать с помощью средств другого языка, а также генерировать креативный продукт, который является лингвистической инноваци$\boldsymbol{e}$, представляющей собой новую речевую единицу, созданную при помощи использования нестандартных способов применения ресурсов языка и речи, для того чтобы реализовать/замаскировать новую идею с целью достижения определенного эффекта. 
В рамках лингвистической креативности мы выделяем: языковую креативность, определяемую как способность индивида распознавать и правильно интерпретировать лингвистические инновации; neреводческую креативность, представляющую собой умение использовать творческий подход к передаче лингвистических инноваций средствами другого языка, и литературную креативность, связанную со способностью создавать лингвистические инновации и реализовывать их в текстах разной семиотической и жанровой принадлежности.

Литературная креативность в первую очередь является характеристикой деятельности писателей, сценаристов, журналистов, а также копирайтеров и т. п. При этом следует отметить, что умение создавать тексты, выполняющие необходимые функции и приводящие к созданию необходимого эффекта, является необходимым навыком не только тех, чья профессиональная деятельность непосредственно связана с литературным творчеством, но и тех, кто использует данную способность в повседневном общении (устном или письменном). Литературная креативность может быть востребована и в переводческой деятельности, поскольку при переводе коммуникативных актов, например содержащих языковую игру, переводчик зачастую не столько передает языковую игру, представленную в оригинале, сколько создает новую.

Одной из наиболее сложных задач, требующих творческого подхода, является копирайтинг (написание текстов с целью рекламы или других форм маркетинга), а также нейминг (тип копирайтинга), связанный с созданием уникального креативного названия, заголовка и др. Одним из наиболее популярных способов создания креативного заголовка является языковая игра, которая получает все большее распространение в текстах как разной семиотической принадлежности (например, вербальный, креолизованный, аудиовизуальный и др.), так и разной жанровой принадлежности (например, реклама, заголовок, мем и др.).

\section{Материалы и методы}

Целью данной работы является исследование специфики использования техник формирования идей (Ideation techniques) для создания лингвистических инноваций.

Цель работы обусловила необходимость решения следующих задач: 1) выявить техники формирования идей, которые могут быть применены для решения задач, связанных с созданием лингвистических инноваций; 2) описать способы адаптации техник; 3) апробировать отобранные техники при решении нейминг-задачи; 4) выявить особенности влияния использования отобранных техник на специфику решения задачи и определить дальнейшие перспективы их применения.

В работе предпринимается попытка сформировать и адаптировать набор техник формирования идей для решения нейминг-задачи, связанной с использованием языковой игры, который в дальнейшем может получить практическое применение при решении аналогичных задач.

Для решения нестандартной проблемы и получения креативного продукта, в данном случае названия, требуются нестандартные подходы. Исследователи отмечают: «Реализация нестандартных подходов в процессе достижения значимых целей обусловливает степень эффективности решения задач. Подобные подходы очень часто называют креативными, сам процесс креативным, и результатом, как правило, являются креативные продукты» [19, с. 15].

Цель эксперимента, проводимого в работе, заключается в том, чтобы определить целесообразность использования техник формирования идей для решения задач, связанных с созданием лингвистических инноваций, а именно для создания названия книги, посвященной исследованию языковой игры: 1) как лингвистического явления, связанного с нестандартными способами использования ресурсов языка и речи при создании новых речевых форм для достижения комического эффекта, и 2) как явления, представляющего особую сложность при переводе. Согласно условиям нейминг-задачи название книги должно содержать языковую игру и может: 1) отражать один или оба аспекта, указанных в задании; 2) быть на русском и английском языках. Для выполнения задания предполагалось использовать термины «языковая игра», «игра слов», «каламбур», их эквиваленты в английском языке «language game», «verbal play», «word play» («wordplay», «play on words»), «pun», а также синонимы и близкие по значению слова.

Одним из наиболее востребованных подходов для решения творческих задач является использование техник формирования идей.

Техники формирования идей. В настоящее время существуют различные техники формирования идей, для обозначения которых в разных источниках используются термины «метод», «техника», «способ», «стратегия» и др. В рамках данной работы предпочтение отдается термину «техника». Было выявлено более ста двадцати различных техник. Предлагаемые техники ориентированы на разные цели (решение проблемы, создание нового продукта) и разное количество пользователей (групповые, индивидуальные); имеют разную сложность исполнения (простые, сложные) и разную степень четкости структурированности и детализации (четкие, размытые); разную профессиональную ориентированность (искусство, 
бизнес, педагогика и др.). Следует отметить отсутствие единого подхода как к формальной, так и к содержательной составляющей различных техник.

Существуют различные наборы техник, которые сформированы в соответствии с целью применения и типом профессиональной деятельности, например, техники, предназначенные для маркетологов и производителей рекламы (мозговой штурм и его разновидности, корабельный совет, метод фокальных объектов, синектика, оператор РВС (размер, время, стоимость), конференция идей, метод гирлянд ассоциаций и метафор, метод маленьких человечков, метод контрольных вопросов, морфологический анализ, методика слома стереотипа [20]), для веб-писателей (freewriting, looping, listing, clustering, nutshelling, cubing, Journalistic 5W's and 1H, researching [21]), для копирайтеров (абстрагирование, фиксация идей, метод автоматической записи, использование символов, амплификация, метод игры, метод инверсии, метод агглютинации, метод фокальных объектов и др. [22]), для писателей (word storm, word association, mind maps, word bank, visual association [23]) и др. В большинстве случаев предлагается от пяти до двенадцати техник. К универсальным техникам можно отнести такие техники, как мозговой штурм, морфологический анализ, синектика, ментальные карты, SCAMPER и прототипирование.

Для решения нейминг-задачи, связанной с созданием уникального, звучного и запоминающегося названия, было отобрано 8 техник, которые могут быть использованы в индивидуальной работе и в большей степени могут быть адаптированы к выполнению поставленного задания: Морфологическая матрица (Morphological Matrix), Синектика (Synectics), Любитель понятий (Concept Fan), SCAMPER, Метафора ZMET (Metaphor ZMET), Перефразирование ключевых слов (Paraphrasing Kеу Words), Случайный стимул (Random Stimulus) и Супергерои (Superheroes).

Среди них в соответствии с классификацией, предлагаемой в работе Ж. Ванг [24, р. 58], выделены: 1) универсальные наиболее часто применяемые техники, которые, как правило, имеют четкие инструкции, сопровождаются большим количеством примеров и не требуют больших ресурсов для использования (Morphological Matrix и Synectics); 2) специальные техники, применимые для специальных целей и ситуаций, имеющие высокий уровень структурной сложности, требующие бо́льших ресурсов и времени (Concepts Fan и Scamper); 3) техники, в меньшей степени применимые в предпринимательской деятельности (Metaphor (ZMET) и Paraphrasing Key Words); 4) техники, не имеющие официальных стандартов, сложные в применении (Random Stimulus и Super Heroes).
Морфологическая матрица. Данная техника была разработана Ф. Цвики [25]. Суть техники заключается в том, чтобы существующий продукт разложить на части, определить их функции и возможные способы использования, а затем снова объединить для создания новых форм, продуктов или систем.

Адаптация. Была предпринята попытка разложить на составляющие термин «языковая игра» и, переосмыслив полученные сегменты, вновь объединить их, в результате были созданы следующие варианты названия: «Языковая игра - игра языков (А-Я)», «Игра в языке: язык в игре». Разложение на составляющие английских терминов «шord play» и «language game» и их производных: playfully (play + fully), gaming (gam + ing), а также перестановка и преобразование полученных компонентов привели к созданию следующих вариантов: «Wordplay translation: playfully or play foully» и «Pun: gameful playing playful gaming» (где gaming: 1) проведение игр; 2) игорный бизнес).

Синектика (др.-греч. - «совмещение разнородных элементов»). Данная техника была описана в работах У. Гордона [26] и Дж. Принса [27], ее суть заключается в поиске аналогий (прямых, субъективных, символических и фантастических) и их противопоставлении для поиска новых решений.

Адаптация. Сформирована таблица, в первой колонке которой записаны прямые аналогии для термина «языковая игра»: весело, шумно, остроумно, play a game, победa, а во второй - непрямые, отрицающие признаки, описанные в прямых аналогиях: не до веселья, не до смеха, не остро, слезы, game a play, проигрыш. На основе полученных противопоставлений были созданы следующие варианты: «Перевод языковой игры: смех сквозь слезы», «Перевод игры слов: не до игр», Языковая игра: победители и проигравшие», "Pun translation: play or game?», "Pun translation: laugher through tears».

Любитель понятий. Данная техника описывается в работе Э. де Боно [28]. Ее суть заключается в том, чтобы «сделав шаг назад» от основной идеи, получить возможность посмотреть на проблему под более широким углом зрения и выявить связующие понятия, благодаря которым можно сформировать альтернативные идеи.

Адаптация данной техники к решению нейминг-задачи заключается в том, чтобы выявить слова, находящиеся в том же семантическом поле, например: (1) острота, witticism; (2) шутка, joke, а также их производные, которые затем могут быть использованы при создании новых названий. В результате были сформированы следующие варианты: «Языковая шутка в переводе: шутка ли?», а также «Языковая игра в переводе: поиграем?», «Translating wordplay: let's play» (по аналогии структуры); «Ocmpombl 8 
nереводе: острее острого», а также «S(word) play in translation» (по аналогии прил. ocmpый $->$ сущ. unaгa (sword)) и «Word play - worth play» (по аналогии сущ. word (слово) $\rightarrow>$ прил. worth (худший))».

SCAMPER. Авторами техники являются А. Осборн [29] и Б. Эберле [30]. В названии данной техники используется аббревиатура SCAMPER: Substitute (замени), Combine (соедини), Adapt (адаптируй), Modify (модифицируй), Put to different use (предложи разное использование), Eliminate (устрани), Reverse (переверни). Техника основана на поиске ответов на сгруппированные по темам прямые вопросы о том, как можно развить и усовершенствовать существующий продукт или сервис.

Адаптация. При поиске ответов на вопросы, относимые к группе «М» - модифицируй, было получено несколько вариантов идей: Вопрос 1. Какие идиомы и каким образом можно модифицировать? Варианты: «Перевод каламбура: пан или пропал», «Перевод языковой игры, или ум за разум», «Перевод языковой игры: хорошо смеется тот, кто смеется последним», «Verbal humour translation: He laughs best that laughs last». Вопрос 2. Какие прецедентные тексты и каким образом можно модифицировать? Варианты: «Game of Word Play» по аналогии с названием фильма «Game of Thrones» («Игра престолов» 2011 г.), «Языковая игра по правилам и без» («Любовь по правилам и без» 2003 г.).

Memaфора (ZMET-Zaltman metaphor elicitation technique). Техника извлечения метафор была разработана Дж. Зальтманом [31]. Данная техника используется в нейромаркетинге для выявления подсознательных желаний покупателей. Ее суть заключается в извлечении из бессознательного метафорических образов, которые оказывают воздействие на восприятие информации.

Адаптация. В рамках данной работы метафорический образ предполагалось создать с помощью визуального изображения, которое может быть размещено на обложке книги. В данном случае также была использована техника прототипирования (Prototyping), связанная с созданием прототипа, процесс изготовления которого стимулирует появление новых идей. В полученных вариантах были использованы изображения шахмат и лампочек. В результате были сформированы следующие варианты: «Word play translation: to win not possible to lose», «Перевод языковой игры: победить нельзя проиграть», «Языковая игра: твой ход», "Pun translation: ignite your creativity».

Перефразирование ключевых слов. Данная техника была предложена Э. де Боно [32]. Ее суть заключается в том, чтобы «перефразировать цели», заменив ключевые слова в формулировке проблемы или задачи для получения альтернативных решений. В этом случае предполагается перечисление как можно большего количества синонимов, а также, при необходимости выхода на более абстрактный уровень, антонимов и ассоциаций.

Адаптация. Была предпринята попытка перефразирования ключевых терминов. Цепочка словосочетаний на русском языке «языковая игра $\rightarrow>$ языковая забава $\rightarrow$ лингвистическая забава $\rightarrow$ лингвистическая острота $\rightarrow$ речевая острота» позволила создать варианты: «Остроты в речи: острее, чем вы думали», «Языковая игра: используйте остроты для придания остроты». Цепочка словосочетаний на английском языке: «play on words $\rightarrow$ play on swords $\rightarrow$ game of swords» привела к созданию варианта: «Pun translation: play on words or game of swords?».

Random Stimulus. Суть данной техники заключается в том, чтобы использовать для создания новой идеи случайные свободные ассоциации, появившиеся в течении определенного промежутка времени.

Адаптащия. Использование трех различных ассоциаций привело к созданию следующих вариантов: «Translation: Pun and Punishment» (право); «Язык в игре и вне игры» (футбол); "Translating word play: 2get or 4get? », «Translating pun: 2give or 4give?» (сходство звучания предлогов и названий цифр).

Cуnергерои. Суть данной техники заключается в том, чтобы представить себя супергероем или известной личностью и предположить, каким образом данный персонаж мог бы решить поставленную задачу при помощи своих суперспособностей.

Адаптащия. В рамках данного эксперимента при выборе известной личности предпочтение было отдано писателю, имеющему выдающиеся языковые способности, В. В. Набокову, который использовал в своих произведениях каламбуры на разных языках (например, «I pressed the bell button, it vibrated through my whole system. Personne. Je resonne. Repersonne» [33, p. 307]; «Я нажал на кнопку звонка; его вибрация прошла по всему моему составу. Никого. Звоню вновь. Никовновь» [34, с. 368]. Была предпринята попытка создать названия-полиглоты: «Перевод игры c love», «Перевод языковой игры:: Рип или пропал». В этом случае техника «Супергерои» был использована в сочетании с техникой «Морфологическая матрица».

\section{Результаты исследования}

Опытно-экспериментальная проверка эффективности техник показала, что их использование способствует улучшению количества и качества вариантов решения творческой задачи. Было сформировано 35 идей названия (18 русских, 15 английских и 2 названия, сочетающие в себе языковые единицы двух языков). Техники оказались более продуктивными для создания названий, в которых делается акцент на проблеме, а именно переводе языковой игры (22 ва- 
рианта), в то время как для названия, в котором проблема перевода не отражена, предложено 13 вариантов. Было выявлено, что и техники с наибольшим общим количеством вариантов: SCAMPER, Синектика, Любитель понятий (по 6 вариантов), и техники с наибольшим количеством удачных вариантов: SCAMPER, Морфологическая матрица и Метафоры (по 4 варианта), имеют разную степень структурированности, сложности исполнения и универсальности использования.

Одними из наиболее удачных вариантов являются: «Языковая игра - игра языков (А-Я)» и «Gате of Word Play», а также «Перевод игры с Love», "Перевод языковой игры:: победить нельзя проиграть», и «Wordplay translation: playfully or play foully». Окончательный выбор названия будет зависеть от контекста, мнения заказчика, а также от способности названия привлечь внимание потенциального читателя. Безусловно, продуктивность техник будет зависеть от специфики задания. В данном случае наиболее продуктивными оказались техники, относимые ко второй группе, имеющие более высокий уровень структурной сложности, требующие больших ресурсов и времени для применения: Морфологическая матрица, SCAMPER и Метафоры (таблица).

В большинстве случаев при анализе названий нет возможности определить, какая техника применялась в том или ином случае. Это говорит о том, что для получения наилучшего результата данные техники следует использовать в комплексе.

\section{Заключение}

Использование представленного набора техник формирования идей является целесообразным и оправданным, поскольку позволяет не только минимизировать возникновение тупиковых ситуаций и экономить время при решении творческих задач, но и способствует значительному повышению личной креативности.

Материалы статьи могут быть использованы преподавателями филологических дисциплин для развития лингвистической креативности у студентов на этапе получения высшего образования. Результаты исследования также представляют практическую ценность для практикующих писателей, журналистов,

Использование техник формирования идей для решения нейминг-задачи

\begin{tabular}{|c|c|c|}
\hline $\begin{array}{c}\text { Техники } \\
\text { формирования идей }\end{array}$ & Русский язык & Английский язык \\
\hline $\begin{array}{l}\text { Морфологическая } \\
\text { матрица }\end{array}$ & $\begin{array}{l}\text { Языковая игра - игра языков (А-Я)*. } \\
\text { Игра в языке: язык в игре }\end{array}$ & $\begin{array}{l}\text { Pun: 'gameful playing' - playful gaming. } \\
\text { Wordplay translation: playfully or play } \\
\text { foully }\end{array}$ \\
\hline Синектика & $\begin{array}{l}\text { Перевод языковой игры: смех сквозь слезы. } \\
\text { Перевод игры слов: не до игр. } \\
\text { Языковая игра: победители и проигравшие. } \\
\text { Языковая игра: проигрыш или выигрыш }\end{array}$ & $\begin{array}{l}\text { Pun translation: play or game? } \\
\text { Pun translation: laugher through tears }\end{array}$ \\
\hline Любитель понятий & $\begin{array}{l}\text { Языковая шутка в переводе: шутка ли? } \\
\text { Языковая игра в переводе: поиграем? } \\
\text { Остроты в переводе: острее острого }\end{array}$ & $\begin{array}{l}\text { Translating wordplay: let's play. } \\
\text { S(word) play in translation. } \\
\text { Word play - worth play }\end{array}$ \\
\hline SCAMPER & $\begin{array}{l}\text { Перевод каламбура: пан или пропал. } \\
\text { Перевод языковой игры, или ум за разум. } \\
\text { Перевод языковой игры: хорошо смеется тот, кто } \\
\text { смеется последним. } \\
\text { Языковая игра по правилам и без } \\
\end{array}$ & $\begin{array}{l}\text { Verbal humour translation: He laughs best } \\
\text { that laughs last. } \\
\text { Game of Word Play }\end{array}$ \\
\hline Memaфopa & $\begin{array}{l}\text { Перевод языковой игры: победить нельзя } \\
\text { проиграть. } \\
\text { Языковая игра: твой ход }\end{array}$ & $\begin{array}{l}\text { Word play translation: to win not possible } \\
\text { to lose. } \\
\text { Pun translation: ignite your creativity }\end{array}$ \\
\hline $\begin{array}{l}\text { Перефразирование } \\
\text { ключевых слов }\end{array}$ & $\begin{array}{l}\text { Остроты в речи: острее, чем вы думали. } \\
\text { Языковая игра: используйте остроты для придания } \\
\text { остроты }\end{array}$ & $\begin{array}{l}\text { Pun translation: play on words or game of } \\
\text { swords? }\end{array}$ \\
\hline Случайный стимул & Язык в игре и вне игры & $\begin{array}{l}\text { Translation: Pun and Punishment. } \\
\text { Translating wordplay: 2get or 4get? } \\
\text { Translating pun: 2give or 4give? }\end{array}$ \\
\hline $\begin{array}{l}\text { Супергерои } \\
(2 \text { варианта) }\end{array}$ & \multicolumn{2}{|l|}{$\begin{array}{l}\text { Перевод игры с love. } \\
\text { Перевод языковой игры: pun или пропал }\end{array}$} \\
\hline
\end{tabular}


копирайтеров и переводчиков, которые могут использовать предложенный набор техник при решении профессиональных задач.

В дальнейшем представляется целесообразным исследование особенностей использования техник формирования идей при обучении переводу коммуникативных актов, содержащих языковую игру, которые представляют особую сложность для переводчика и требуют переводческой креативности.

\section{ЛИТЕРАТУРА}

1. Ваулина Т. А., Зуева Д. Е. Проблема развития креативности в мировом образовательном пространстве // Вестник Том. гос. ун-та. 2011. № 351. С. 121-123.

2. Bloom B. S. (ed.). Developing talent in young people. New York : Ballantine Books, 1985. 572 p.

3. Westby E. L., Dawson V. L. Creativity : Asset or burden in the classroom? // Creativity Research Journal. 1995. № 8. Pp. 1-10.

4. Beghetto R. A. Ideational code-switching : Walking the talk about supporting student creativity in the classroom // Roeper Review. 2007. № 29. Pp. 265-270.

5. Kaufman J. C. Genius, lunatics, and poets : Mental illness in prize-winning authors // Imagination, Cognition, and Personality. 2001. № 20. Pp. 305-314.

6. Kaufman J. C., Gentile C. A., Baer J. Do gifted student writers and creative writing experts rate creativity the same way? // Gifted Child Quarterly. 2005. № 49. Pp. 260-265.

7. Kaufman S. B., Kaufman J. C. Ten years to expertise, many more to greatness : an investigation of modern writers // Journal of Creative Behavior. 2007. № 41. Pp. 114-124.

8. Torrance E. P., Mayers R. E. Creative Learning and Teaching. NY : Dodd, Mead and Co., 1970. 343 p.

9. Мороз В. В. Развитие креативности студентов : монография. Оренбург : ОГУ, 2011. 183 с.

10. Welsch $P$. $K$. The nurturance of creative behavior in educational environments : a comprehensive curriculum approach. Unpublished Doctoral Dissertation. University of Michigan, 1980. 272 p.

11. Боровинская Д. Н. К вопросу о классификации теорий креативности // Вестник Том. гос. ун-та. 2014. № 385. С. 50-56.

12. Галкина $A$. B. Педагогические условия развития лингвистической креативности в переводческой деятельности студентов // Вестник ТГУ. 2011. № 12 (104). C. 131-136.

13. Базилевич В. Б. Языковая игра как форма проявления лингвистической креативности // Филологические науки. Вопросы теории и практики. Тамбов, 2015. № 8 (50), ч. III. C. 20-22.

14. Гарднер Г. Структура разума : теория множественного интеллекта : пер. с англ. М. : Вильямс, 2007. $512 \mathrm{c}$.

15. Халюшова Г. А. Развитие лингвистической креативности студента университета : автореф. дис. ... канд. пед. наук. Оренбург, 2005. 198 с.
16. Тюленева Т. В. Формирование лингвистической креативности студентов неязыковых специальностей : автореф. дис. ... канд. пед. наук. Волгоград, 2012. 211 с.

17. Гридина T. А. Языковая игра : стереотип и творчество : монография. Екатеринбург : Урал. гос. пед. ун-т, 1996. 214 c.

18. Гридина T. А. Экспериментальный ресурс диагностики и тренинга вербальной креативности // Филологический класс. 2014. № 2 (36). С. 30-35.

19. Боровинская Д. Н., Суровиев В. А. Креативность и мышление : категориальная характеристика // Вестник Том. гос. ун-та. Философия. Социология. Политология. 2019. № 47. C. 15-24.

20. Дмитриева М. Л. Все основные креативные приемы выработки идей : исчерпывающий анализ 13 практических методик // Элитариум (Центр дополнительного образования). 2019. URL: http://www. elitarium.ru/kreativnoe-myshlenie-ideya-tvorchestvometod-obekt-ehlement-priznak-analogiya-reshenie-produktsinonim-stereotip-reklama-brend/

21. William D. K. 8 Brainstorming Strategies for Generating New Writing Ideas // The Web Writer Spotlight. 2019. URL: https://webwriterspotlight.com/8-brainstormingstrategies-for-generating-new-writing-ideas

22. Акулич M. Конспект копирайтера // Энциклопедия маркетинга. 2018. URL: https://www.marketing.spb. $\mathrm{ru} /$ lib-comm/advert/copywriter_summary.htm\# glava9

23. Neidlinger J. 4 Reasons you should brainstorm if you want to become a better writer // CoSchedule blog. 2019. URL: https://coschedule.com/blog/brainstormingtechniques/

24. Wang Z. Effects based stimulation of ideas in design and engineering. A thesis submitted for the degree of Doctor of Philosophy. Imperial College London Mechanical Engineering Department, 2013. 286 p.

25. Zwicky F. Discovery Invention, Research Through the Morphological Approach. McMillan, 1969. 276 p.

26. Gordon W. J. J. Synectics. NY : Harper \& Row, 1961. $180 \mathrm{p}$.

27. Prince G. M. The practice of creativity. NY : Harper \& Row, 1970. 272 p.

28. Bono E. de. Serious Creativity : Using the Power of Lateral Thinking to Create New Ideas. Harper Business, $1992.338 \mathrm{p}$.

29. Osborn A. F. Applied imagination; principles and procedures of creative problem-solving. Charles Scribner's Sons, 1957. $379 \mathrm{p}$.

30. Eberle R. F. Scamper : Games for Imagination Development. Buffalo, NY : D.O.K. Publishers, 1971. 96 p.

31.Zaltman G. How Consumers Think : Essential Insights into the Mind of the Market. Harvard Business School Press, 2003. 323 p.

32. Bono E. de. Lateral Thinking : a textbook of creativity. London, 1970. 272 p.

33. Nabokov V. V. Lolita. London : Penguin Books, 2006. $361 \mathrm{p}$.

34. Набоков В. В. Лолита : пер. с англ. автора / общ. ред. К. Красник. СПб. : Азбука, 2015. 448 с. 


\section{REFERENCES}

1. Vaulina T. A., Zueva D. E. Problema razvitiya kreativnosti $v$ mirovom obrazovatel'nom prostranstve [The problem of creativity development in the world educational space]. In: Vestn. Tom. gos. un-ta. 2011. No. 351. Pp. 121123.

2. Bloom B. S. (Ed.). Developing talent in young people. New York: Ballantine Books, 1985. 572 p.

3. Westby E. L., Dawson V. L. Creativity: Asset or burden in the classroom? In: Creativity Research Journal. 1995. No. 8. Pp. 1-10.

4. Beghetto R. A. Ideational code-switching: Walking the talk about supporting student creativity in the classroom. In: Roeper Review. 2007. No. 29. Pp. 265-270.

5. Kaufman J. C. Genius, lunatics, and poets: Mental illness in prize-winning authors. In: Imagination, Cognition, and Personality. 2001. No. 20. Pp. 305-314.

6. Kaufman J. C., Gentile C. A., Baer J. Do gifted student writers and creative writing experts rate creativity the same way? In: Gifted Child Quarterly. 2005. No. 49. Pp. 260-265.

7. Kaufman S. B., Kaufman J. C. Ten years to expertise, many more to greatness: An investigation of modern writers. In: Journal of Creative Behavior. 2007. No. 41. Pp. 114-124.

8. Torrance E. P., Mayers R. E. Creative Learning and Teaching. NY: Dodd, Mead and Co., 1970. 343 p.

9. Moroz V. V. Razvitie kreativnosti studentov [Development of students' creativity]: monografiya. Orenburg: OGU, 2011. 183 p.

10. Welsch P. K. The nurturance of creative behavior in educational environments: A comprehensive curriculum approach. Unpublished Doctoral Dissertation, University of Michigan. 1980. 272 p.

11. Borovinskaya D. N. K voprosu o klassifikatsii teorij kreativnosti [On the classification of theories of creativity]. In: Vestnik Tomskogo gosudarstvennogo universiteta. 2014. No. 385. Pp. 50-56.

12. Galkina A. V. Pedagogicheskie usloviya razvitiya lingvisticheskoj kreativnosti v perevodcheskoj deyatel'nosti studentov [Pedagogical conditions for the development of linguistic creativity in the translation activity of students]. In: Vestnik TGU. 2011. No. 12 (104). Pp. 131-136.

13. Bazilevich $V$. B. Yazykovaya igra kak forma proyavleniya lingvisticheskoj kreativnosti [Language play as a form of manifestation of linguistic creativity]. In: Filologicheskie nauki. Voprosy teorii i praktiki. Tambov: Gramota, 2015. No. 8 (50), ch. III. Pp. 20-22.

14. Gardner G. Struktura razuma: teoriya mnozhestvennogo intellekta [The Structure of Mind: Theory of Multiple Intelligences] / per. s angl. M.: OOO «I.D. Vil'yams», 2007. 512 p.

15. Khalyushova G. A. Razvitie lingvisticheskoj kreativnosti studenta universiteta [Development of linguistic creativity of a university student]: avtoref. dis. ... kand. ped. nauk / Gul'fiya Al'myansurovna Khalyushova. Orenburg, 2005. 198 p.

16. Tyuleneva T. V. Formirovanie lingvisticheskoj kreativnosti studentov neyazykovykh spetsial'nostej
[Formation of linguistic creativity of students of nonlinguistic specialties]: avtoref. dis. ... kand. ped. nauk. Volgograd, 2012. $211 \mathrm{p}$.

17. Gridina T. A. Yazykovaya igra: stereotip $i$ tvorchestvo [Language game: stereotype and creativity]: monografiya. Ekaterinburg: Ural. gos. ped. un-t, 1996. 214 p.

18. Gridina T. A. Eksperimental'nyj resurs diagnostiki i treninga verbal'noj kreativnosti [Experimental resource for diagnostics and training of verbal creativity]. In: Filologicheskij klass. 2014. No. 2 (36). Pp. 30-35.

19. Borovinskaya D. N., Surovtsev V. A. Kreativnost' i myshlenie: kategorial'naya kharakteristika [Creativity and thinking: categorical characteristics]. In: Vestn. Tom. gos. un-ta. Filosofiya. Sotsiologiya. Politologiya. 2019. No. 47. Pp. 15-24.

20. Dmitrieva M. L. Vse osnovnye kreativnye priemy vyrabotki idej: ischerpyvayushhij analiz 13 prakticheskikh metodik [All Essential Idea Generation Creative Techniques: A Comprehensive Analysis of 13 Practical Techniques]. In: Elitarium (Tsentr dopolnitel'nogo obrazovaniya) 2019. Available at: http://www.elitarium.ru/kreativnoe-myshlenieideya-tvorchestvo-metod-obekt-ehlement-priznakanalogiya-reshenie-produkt-sinonim-stereotip-reklamabrend/

21. William D. K. 8 Brainstorming Strategies for Generating New Writing Ideas. In: The Web Writer Spotlight. 2019. Available at: https://webwriterspotlight.com/8brainstorming-strategies-for-generating-new-writing-ideas

22. Akulich M. Konspekt kopirajtera [Copyrighter summary]. In: Entsiklopediya marketinga. 2018. Available at: https://www.marketing.spb.ru/lib-comm/advert/ copywriter_summary.htm\# glava9

23. Neidlinger J. 4 Reasons you should brainstorm if you want to become a better writer. In: CoSchedule blog. 2019. Available at: https://coschedule.com/blog/ brainstorming-techniques/

24. Wang Z. Effects based stimulation of ideas in design and engineering. A thesis submitted for the degree of Doctor of Philosophy. Imperial College London Mechanical Engineering Department, 2013. 286 p.

25. Zwicky F. Discovery Invention, Research Through the Morphological Approach. McMillan, 1969. 276 p.

26. Gordon W. J. J. Synectics. NY: Harper \& Row, 1961. $180 \mathrm{p}$.

27. Prince G. M. The practice of creativity. NY: Harper \& Row, 1970. 272 p.

28. Bono E. de. Serious Creativity: Using the Power of Lateral Thinking to Create New Ideas. Harper Business, 1992. $338 \mathrm{p}$.

29. Osborn A. F. Applied imagination; principles and procedures of creative problem-solving. Charles Scribner's Sons, $1957.379 \mathrm{p}$.

30. Eberle R. F. Scamper: Games for Imagination Development. Buffalo, NY: D.O.K. Publishers, 1971. 96 p.

31. Zaltman G. How Consumers Think: Essential Insights into the Mind of the Market. Harvard Business School Press, 2003. 323 p. 
32. Bono E. de. Lateral Thinking: a textbook of creativity. London, 1970. 272 p.

33. Nabokov V. V. Lolita. London: Penguin Books, 2006. $361 \mathrm{p}$.

Российская академия народного хозяйства и государственной службы при Президенте Российской Федерачии

Александрова Е. М., кандидат филологических наук, доиент Центра лингвистики и профессиональной коммуникации ИПиНБ

E-mail: elena_751@mail.ru

Поступила в редакиию 1 марта 2021 2.

Принята к публикации 22 марта 2021 г.

Для цитирования:

Александрова Е. М. Развитие лингвистической креативности: техники формирования идей // Вестник Воронежского государственного университета. Серия: Лингвистика и межкультурная коммуникация. 2021. № 2 . C. 6-14. DOI: https://doi.org/10.17308/lic.2021.2/3410
34. Nabokov V. V. Lolita [Lolita]: per. s angl. avtora / obshh. red. K Krasnik. SPb.: Azbuka, 2015. 448 p.

Russian Presidential Academy of National Economy and Public Administration

Aleksandrova E. M., Candidate of Philology, Associate Professor of the Center of Linguistics and Professional Communication (ILNS)

E-mail:elena_751@mail.ru

Received: 1 March 2021

Accepted: 22 March 2021

\section{For citation:}

Aleksandrova E. M. Developing linguistic creativity: ideation techniques. Proceedings of Voronezh State University. Series: Linguistics and Intercultural Communication. 2021. No. 2. Pp. 6-14. DOI: https://doi.org/10.17308/ lic.2021.2/3410 